\title{
New Insight into the Chemical Composition, Antimicrobial and Synergistic Effects of the Moroccan Endemic Thymus atlanticus (Ball) Roussine Essential Oil in Combination with Conventional Antibiotics
}

\author{
Ahmed Nafis ${ }^{1,2, *}$, Marcello Iriti ${ }^{3}{ }^{(0)}$, Lahcen Ouchari ${ }^{4}$, Fatima El Otmani ${ }^{1}$, Najat Marraiki ${ }^{5}$, \\ Abdallah M. Elgorban ${ }^{5}\left(\mathbb{D}\right.$, Asad Syed ${ }^{5}$, Noureddine Mezrioui ${ }^{2}$, Lahcen Hassani ${ }^{2}$ and Luísa Custódio ${ }^{6}(\mathbb{D}$ \\ check for \\ updates \\ Citation: Nafis, A.; Iriti, M.; Ouchari, \\ L.; El Otmani, F.; Marraiki, N.; \\ Elgorban, A.M.; Syed, A.; Mezrioui, \\ N.; Hassani, L.; Custódio, L. New \\ 1 Microbiology, Health and Environment Team, Faculty of Sciences, Chouaib Doukkali University, \\ El Jadida 24000, Morocco; elotmanifatima@yahoo.fr \\ 2 Laboratory of Microbial Biotechnologies, Agrosciences and Environment, Faculty of Sciences Semlalia, \\ Cadi Ayyad University, Marrakech 40000, Morocco; mezrioui@uca.ac.ma (N.M.); lhassani@uca.ac.ma (L.H.) \\ 3 Department of Agricultural and Environmental Sciences, Milan State University, via G. Celoria 2, \\ 20133 Milan, Italy; marcello.iriti@unimi.it \\ 4 Moroccan Coordinated Collection of Microorganisms (CCMM), National Center for Scientific and Technical \\ Research (CNRST), P.O. Box 8027, Rabat 10102, Morocco; ouchari@cnrst.ma \\ 5 Department of Botany and Microbiology, College of Science, King Saud University, P.O. Box 2455, \\ Riyadh 11451, Saudi Arabia; najat@ksu.edu.sa (N.M.); aelgorban@ksu.edu.sa (A.M.E.); \\ assyed@ksu.edu.sa (A.S.) \\ 6 Center of Marine Sciences, Faculty of Sciences and Technology, University of Algarve, Ed. 7, Campus of \\ Gambelas, 8005-139 Faro, Portugal; lcustodio@ualg.pt \\ * Correspondence: ahmed.nafis@edu.uca.ac.ma; Tel.: +212-610170760
}

Insight into the Chemical

Composition, Antimicrobial and

Synergistic Effects of the Moroccan

Endemic Thymus atlanticus (Ball)

Roussine Essential Oil in

Combination with Conventional

Antibiotics. Molecules 2021, 26, 5850

https://doi.org/10.3390/

molecules26195850

Academic Editor: Eun Kyoung Seo

Received: 19 August 2021

Accepted: 20 September 2021

Published: 27 September 2021

Publisher's Note: MDPI stays neutral with regard to jurisdictional claims in published maps and institutional affiliations.

Copyright: (C) 2021 by the authors Licensee MDPI, Basel, Switzerland. This article is an open access article distributed under the terms and conditions of the Creative Commons Attribution (CC BY) license (https:// creativecommons.org/licenses/by/ $4.0 /)$

\begin{abstract}
This study reported the volatile profile, the antimicrobial activity and the synergistic potential of essential oil (EO) from the Moroccan endemic Thymus atlanticus (Ball) Roussine, in combination with the antibiotics ciprofloxacin and fluconazole for the first time, to the best of our knowledge. The EO chemical composition was determined by gas chromatography coupled to mass spectrometry (GC-MS) analysis and the antimicrobial activity assessed by the disc diffusion method against three Gram positive (Bacillus subtilis, Micrococcus luteus, Staphylococcus aureus) and three Gram-negative bacteria (Pseudomonas aeruginosa, Escherichia coli and one clinical isolate, Klebsiella pneumonia). The antifungal activity was evaluated in four pathogenic yeasts (Candida albicans, C. glabrata, C. krusei and C. parapsilosis). The minimum inhibition concentration (MIC) and the synergistic effect with ciprofloxacin and fluconazole were determined by the two-fold dilution technique and checkerboard test, respectively. Twenty-one constituents were identified by GC-MS in the EO, including carvacrol $(21.62 \%)$ and borneol $(21.13 \%)$ as the major components. The EO exhibited a significant antimicrobial activity with inhibition zones ranging from $0.7 \mathrm{~mm}$ to $22 \mathrm{~mm}$ for P. aeruginosa and B. subtilis, respectively, and MIC values varying from $0.56 \mathrm{mg} / \mathrm{mL}$ to $4.47 \mathrm{mg} / \mathrm{mL}$. The fractional inhibitory concentration index (FICI) values ranged from 0.25 to 0.50 for bacteria and from 0.25 to 0.28 for yeasts. The maximum synergistic effect was observed for K. pneumonia with a 256-fold gain of antibiotic MIC. Our results have suggested that EO from T. atlanticus may be used alone or in association with antibiotics as a new potential alternative to prevent and control the emergence of resistant microbial strains both in the medical field and in the food industry.
\end{abstract}

Keywords: thyme; Moroccan endemic plant; essential oil; antimicrobial activity; synergy; antibiotic resistance

\section{Introduction}

Morocco is an important reservoir of biodiversity and Mediterranean speciation with an important flora of around 3913 taxa, including 1298 subspecies in 981 genera and 
155 families. This Moroccan plant biodiversity is characterized by a high percentage of endemic species (22\%), comprising 878 endemic taxa with 599 taxa at the species level [1].

The genus Thymus, belonging to the Lamiaceae family, is widely distributed in Morocco with 11 endemic species, including Thymus atlanticus (Ball) Roussine, locally known as "Azukni". This thyme species is characterized by very small white or pale pink flowers with revolute leaves or subplanes, glabrescent and in the form of a condensed carpet. It is the smallest of the Moroccan thymes, and very polymorphic depending on altitude and ecology, growing between 1700 to $3400 \mathrm{~m}$ [2]. For a long time, thyme has been commonly used in traditional Moroccan medicine to treat many chronic diseases, especially those related to the digestive system and skin lesions infected with eczema or pathogenic fungi such as Trichophyton rubrum [3,4]. Moreover, some studies have reported that a T. atlanticus aqueous extract from leaves exhibits relevant anti-inflammatory and antioxidant activities due to its high content in total phenolic compounds [5]. In addition, Khouya et al. [6] showed that the aqueous polyphenol-rich extract of this plant inhibited the blood coagulation ex vivo and in vivo. However, to the best of our knowledge, the antimicrobial activity of T. atlanticus has never been evaluated.

Previous reports showed that Moroccan endemic thymes exhibited important biological properties, including antifungal, antimicrobial, antiviral and antioxidant activities [7-9]. Furthermore, it was demonstrated that extracts from other Moroccan endemic thymes, such as $T$. riatarum, T. maroccanus and T. broussonetii, exhibited a high antimicrobial efficacy in combination with standard antibiotics as new efflux pump inhibitors or as membrane permeabilizers $[7,10]$. In general, the combination of antimicrobial drugs with natural products from medicinal plant characterized by a multicomponent chemical composition and multitarget mechanism of action provides many benefits, such as the decrease of the toxic effects of the combined active ingredients. This new and safe alternative can solve the problem of antimicrobial resistance that has become a serious public health concern with economic, social and medical implications, especially in the case of multidrug-resistant microbes and resulting infections. In this context, this study aimed to evaluate, for the first time, the antimicrobial and antifungal activities of the essential oil obtained from aerial organs of the Moroccan endemic T. atlanticus, along with its synergistic effect with standard antimicrobials (ciprofloxacin and fluconazole).

\section{Results and Discussion}

The steam distillation of T. atlanticus aerial parts provided a yellow oil with a yield of $1.41 \%$, based on dry plant material $(v / w)$. The obtained yield was similar to the values reported for some thyme species, although it was different when compared with others. For example, Fadli et al. [7] reported that the yield of the EOs obtained from T. maroccanus and T. broussonetii were $1.38 \%$ and $1.2 \%$, respectively. In another work, the T. riatarum yield was $0.26 \%$ [10]. Mahboubi et al. [11] obtained yields of Iranian thymes ranging from $2 \%$ to $2.2 \%$ for T. vulgaris and T. daenensis, and from $0.68 \%$ to $1.1 \%$ for T. kotschyanus, T. fedtschenkoi and T. pubescens.

The GC-MS analysis of the T. atlanticus EO revealed the presence of 21 volatile compounds (Table 1 and Figure 1 ) representing $97.44 \%$ of total oil. The major components were carvacrol (21.62\%) and borneol (21.13\%), followed by $\gamma$-terpinene $(9.98 \%), o$-cymene $(8.14 \%)$ and camphene $(7.28 \%)$. Monoterpenes $(88.91 \%)$ were the most represented compounds. Quantitative differences in the chemical profile were noted in comparison with Fadli et al., (2014) in which borneol $(41.67 \%)$ was the most abundant component of the T. riatarum EO, followed by $\alpha$-terpineol $(8.65 \%)$, whereas carvacrol $(0.75 \%)$ was present in small amounts. Fadli et al. [7] also reported a different composition, with carvacrol $(76.35 \%$ and $39.77 \%)$ and borneol $(0.41 \%$ and $12.03 \%)$ as the main constituents of EO from Moroccan endemic thymes (T. maroccanus and T. broussonetii, respectively). A recent study revealed differences in the chemical composition of T. vulgaris EO, where thymol (55.3\%) was identified as the major metabolite [12]. Furthermore, Mahboubi et al. [11] demonstrated that EOs extracted from the Iranian chemotypes T. fedtschenkoi and T. pubescens were rich in thymol $(50.6 \%$ 
and $26.6 \%$, respectively) and carvacrol ( $6.6 \%$ and $27 \%$, respectively). Based on the obtained results, the variation between the chemical composition of our samples and those determined for other thyme species can depend on several factors such as the geographical location, climate, plant material and the season of the material collection [13].

Table 1. Components of essential oil distilled from the leaves of Moroccan endemic T. atlanticus. Entries in bold are major constituents.

\begin{tabular}{ccc}
\hline RI & Abundance $\%$ & Compounds \\
\hline 841 & 1.55 & (E)-2-Hexenal \\
865 & 4.4 & 3-Heptanone \\
953 & $\mathbf{7 . 2 8}$ & Camphene \\
978 & 0.16 & 1-Octen-3-ol \\
991 & 2.77 & $\alpha$-Myrcene \\
1088 & 1.93 & Terpinolene \\
1020 & $\mathbf{8 . 1 4}$ & $o$-Cymene \\
1062 & $\mathbf{9 . 9 8}$ & $\gamma$-Terpinene \\
1026 & 0.43 & cis-Sabinene hydrate \\
1098 & 7.8 & Linalool \\
1078 & 0.23 & cis-4-Thujanol \\
1143 & 0.22 & Camphor \\
1165 & $\mathbf{2 1 . 1 3}$ & endo-Borneol \\
1177 & 1.69 & L-4-terpineol \\
1189 & 4.26 & $\alpha$-Terpineol \\
1242 & 0.34 & Carvone \\
1290 & 1.31 & Thymol \\
1298 & $\mathbf{2 1 . 6 2}$ & Carvacrol \\
1454 & 1.81 & Caryophyllene \\
1526 & 0.15 & $\delta$-Cadinene \\
1581 & 0.24 & Caryophyllene oxide \\
\hline
\end{tabular}

RI: Retention index measured relative to $n$-alkanes (C-9 to C-24) on a non-polar TG-5MS column.

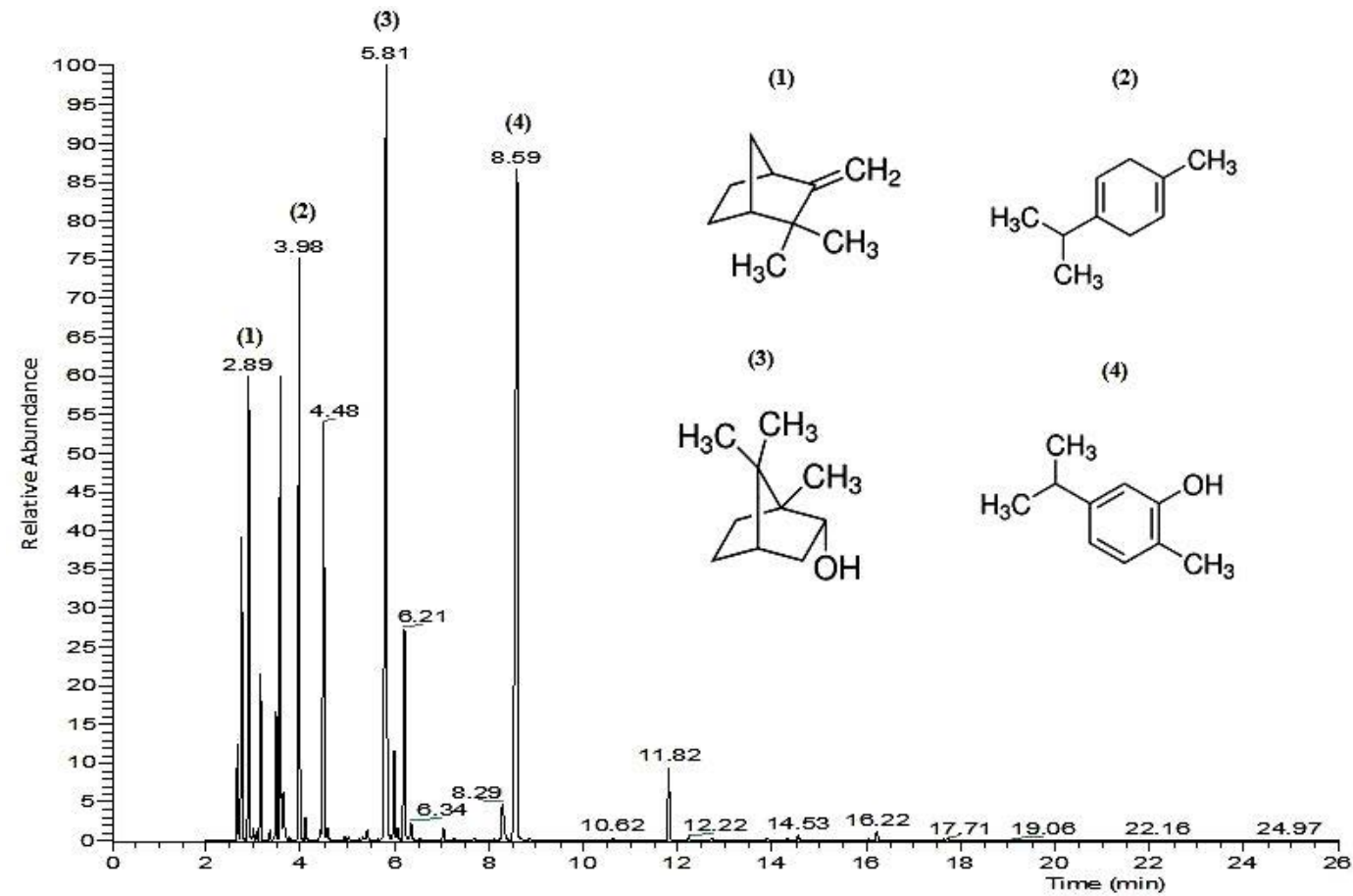

Figure 1. GC-MS chromatogram of T. atlanticus essential oil. (1): Camphene; (2): $\gamma$-Terpinene; (3): Endo-borneol; (4): Carvacrol. 
The disk diffusion assay showed that the EO had a broad-spectrum antimicrobial activity, with inhibition zones (IZ) ranging from $7 \mathrm{~mm}$ (in P. aeruginosa) to $22 \mathrm{~mm}$ (in B. subtilis) (Table 2). The EO showed a powerful inhibitory activity against $B$. subtilis (IZ $=22 \mathrm{~mm}$ ) and both Gram-negative bacteria, namely E. coli $(\mathrm{IZ}=18 \mathrm{~mm})$ and K. pneumoniae $(\mathrm{IZ}=16 \mathrm{~mm})$ (Table 2). The EO also exhibited a high antifungal potential against the pathogenic yeasts C. albicans $(\mathrm{IZ}=15 \mathrm{~mm})$, C. glabrata $(\mathrm{IZ}=18 \mathrm{~mm})$, C. krusei $(\mathrm{IZ}=20 \mathrm{~mm})$ and C. parapsilosis $(\mathrm{IZ}=12 \mathrm{~mm})$ (Table 2). The MIC values showed that the EO inhibited all the tested microorganisms at a concentration of $0.56 \mathrm{mg} / \mathrm{mL}$, except for S. aureus and P. aeruginosa, which were inhibited at $1.12 \mathrm{mg} / \mathrm{mL}$ and $4.47 \mathrm{mg} / \mathrm{mL}$, respectively (Table 2). Remarkably, the Gram-negative bacterium P. aeruginosa seemed to be the least sensitive. Overall, the EO exhibited a significant antimicrobial activity, probably due to its chemical profile rich in carvacrol and borneol. The oxygenated monoterpene cavacrol is a well-known and efficient antimicrobial agent that can damage the cell membrane or other cytoplasmic targets passing through the altered phospholipid bilayer [14-16]. Similarly, the bicyclic monoterpene borneol is also a powerful and broad-spectrum antimicrobial agent able to alter the membrane structural and functional integrity [17]. In addition, other volatile compounds present in lower percentages can also contribute to the biological activity of the EO, including $\gamma$-terpinene, linalool and thymol [18-20]. Concerning the resistance of $P$. aeruginosa, it is well known that a multidrug-resistant bacterium uses many different mechanisms to counteract the antimicrobial drugs [21]. In general, the major mechanisms that $P$. aeruginosa has developed were the lower outer membrane permeability, as intrinsic resistance, and the biofilm formation, as adaptive resistance, that serves as a diffusion barrier to limit the access of bioactive substances into the bacterial cells [22].

Table 2. Inhibition zone (IZ) diameters and minimum inhibitory concentrations (MIC) of the essential oil (EO) extracted from the leaves of Moroccan endemic Thymus. atlanticus against bacteria and yeasts using the disc diffusion and micro-well dilution assays.

\begin{tabular}{|c|c|c|c|c|c|c|}
\hline \multirow[b]{2}{*}{ Microorganisms } & \multicolumn{2}{|c|}{ EO } & \multicolumn{2}{|c|}{ Ciprofloxacin } & \multicolumn{2}{|c|}{ Fluconazole } \\
\hline & $\mathrm{IZ}(\mathrm{mm})$ & $\begin{array}{c}\text { MIC } \\
(\mathrm{mg} / \mathrm{mL})\end{array}$ & $\mathrm{IZ}(\mathrm{mm})$ & $\begin{array}{c}\text { MIC } \\
(\mathrm{mg} / \mathrm{mL})\end{array}$ & $\mathrm{IZ}(\mathrm{mm})$ & $\begin{array}{c}\mathrm{MIC} \\
(\mathrm{mg} / \mathrm{mL})\end{array}$ \\
\hline \multicolumn{7}{|l|}{ Gram-positive bacteria } \\
\hline Staphylococcus aureus & 13.0 & 1.12 & 26.0 & 0.01 & - & - \\
\hline Micrococcus luteus & 12.0 & 0.56 & 27.0 & 0.03 & - & - \\
\hline Bacillus subtilis & 22.0 & 0.56 & 35.0 & 0.01 & - & - \\
\hline \multicolumn{7}{|l|}{ Gram-negative bacteria } \\
\hline Escherichia coli & 18.0 & 0.56 & 12.0 & 0.06 & - & - \\
\hline Klebsiella pneumoniae & 16.0 & 0.56 & 09.0 & 01.0 & - & - \\
\hline $\begin{array}{c}\text { Pseudomonas aeruginosa } \\
\text { Yeasts }\end{array}$ & 07.0 & 4.47 & 08.0 & 0.25 & - & - \\
\hline Candida albicans & 15.0 & 0.56 & - & - & 20.0 & 1 \\
\hline Candida glabrata & 18.0 & 0.56 & - & - & 13.0 & 1 \\
\hline Candida krusei & 20.0 & 0.56 & - & - & 24.0 & 1 \\
\hline Candida parapsilosis & 12.0 & 0.56 & - & - & 28.2 & 1 \\
\hline
\end{tabular}

IZ: inhibition zones (mm). MIC: minimum inhibitory concentration $(\mathrm{mg} / \mathrm{mL})$.

As reported in Tables 3 and 4, a total synergism was observed in the 10 tested combinations of T. atlanticus EO and both antibiotics (ciprofloxacin and fluconazole). The best synergistic effect was recorded in K. pneumoniae and C. parapsilosis, with FICI values of 0.25 . The gain of antibiotic MIC in the presence of EO ranged from 4- to 256-fold. The highest reduction of fluconazole MIC was observed against C. parapsilosis (256-fold), whereas the three other yeast strains had a 32-fold gain. For Gram-positive bacteria, a high decrease was recorded for K. pneumoniae, E. coli and M. luteus, from 256- to 64-fold. Our results showed that the T. atlanticus EO enhanced the antimicrobial activity of the reference antibiotic drugs. Previous studies reported the interaction between antimicrobial agents and other Moroccan thyme EOs. For example, Fadli et al. [10] demonstrated that the addition of 
T. riatarum EO against E. coli AG100 reduced the chloramphenicol MIC from $8 \mathrm{mg} / \mathrm{mL}$ to $2 \mathrm{mg} / \mathrm{mL}$. Similarly, Saad et al. [9] showed that the synergistic effect of T. maroccanus and T. broussonetii EOs, in combination with amphotericin B and fluconazole, resulted in FICI values of $0.49,0.27,0.37$ and 0.3 , respectively, and decreased the antibiotic MICs with more than an 8 -fold gain.

Table 3. Synergistic interaction between T. atlanticus essential oil (EO) and ciprofloxacin against resistant bacteria.

\begin{tabular}{|c|c|c|c|c|c|c|c|c|c|c|c|c|c|c|c|c|c|c|}
\hline & \multicolumn{3}{|c|}{ Micrococcus luteus } & \multicolumn{3}{|c|}{$\begin{array}{c}\text { Staphylococcus } \\
\text { aureus }\end{array}$} & \multicolumn{3}{|c|}{ Bacillus subtilis } & \multicolumn{3}{|c|}{ Escherichia coli } & \multicolumn{3}{|c|}{$\begin{array}{c}\text { Pseudomonas } \\
\text { aeruginosa }\end{array}$} & \multicolumn{3}{|c|}{$\begin{array}{c}\text { Klebsiella } \\
\text { pneumoniae }\end{array}$} \\
\hline & FIC & FICI & Gain & FIC & FICI & Gain & FIC & FICI & Gain & FIC & FICI & Gain & FIC & FICI & Gain & FIC & FICI & Gain \\
\hline $\mathrm{EO}$ & 0.25 & - & - & 0.25 & - & - & 0.25 & - & - & 0.25 & - & - & 0.25 & - & - & 0.25 & - & - \\
\hline Ciprofloxacin & 0.02 & $0.27^{\mathrm{a}}$ & 64 & 0.25 & $0.50^{\mathrm{a}}$ & 4 & 0.06 & $0.31^{\mathrm{a}}$ & 16 & 0.02 & $0.27^{\mathrm{a}}$ & 64 & 0.25 & $0.50^{a}$ & 4 & 0.00 & $0.25^{\mathrm{a}}$ & 256 \\
\hline
\end{tabular}

FIC: fractional inhibitory concentration. FICI: fractional inhibitor concentration index. FIC of oil = MIC of EO in combination with antibiotic/MIC of EO alone. FIC of antibiotic $=$ MIC of antibiotic in combination with EO $/ \mathrm{MIC}$ of antibiotic alone. FIC index $=$ FIC of EO + FIC of antibiotic. ${ }^{\text {a }}$ Total synergism.

Table 4. Synergistic interaction between T. atlanticus essential oil (EO) and fluconazole against clinical pathogenic yeasts.

\begin{tabular}{|c|c|c|c|c|c|c|c|c|c|c|c|c|}
\hline & \multicolumn{3}{|c|}{ Candida albicans } & \multicolumn{3}{|c|}{ Candida glabrata } & \multicolumn{3}{|c|}{ Candida krusei } & \multicolumn{3}{|c|}{ Candida parapsilosis } \\
\hline & FIC & FICI & Gain & FIC & FICI & Gain & FIC & FICI & Gain & FIC & FICI & Gain \\
\hline $\mathrm{EO}$ & 0.25 & - & - & 0.25 & - & - & 0.25 & - & - & 0.25 & - & - \\
\hline Fluconazole & 0.03 & $0.28^{\mathrm{a}}$ & 32 & 0.03 & $0.28^{\mathrm{a}}$ & 32 & 0.03 & $0.28^{\mathrm{a}}$ & 32 & 0.00 & $0.25^{\mathrm{a}}$ & 256 \\
\hline
\end{tabular}

FIC: fractional inhibitory concentration. FICI: fractional inhibitor concentration index. FIC of oil = MIC of EO in combination with antibiotic/MIC of EO alone. FIC of antibiotic $=$ MIC of antibiotic in combination with EO $/ \mathrm{MIC}$ of antibiotic alone. FIC index $=$ FIC of EO + FIC of antibiotic. ${ }^{a}$ Total synergism.

Our results contribute to substantiate the traditional uses of T. atlanticus by the Moroccan populations for the treatment of skin infections caused by different types of microorganisms, thus suggesting that its EO could be further investigated as a natural source of adjuvant agents to be used in combination with conventional antibiotics to reduce the risk of selecting antibiotic resistant microbial strains.

\section{Materials and Methods}

\subsection{Plant Material and Essential Oil (EO) Distillation}

The aerial parts of T. atlanticus were collected by M. Brahim Oummad in September 2019 from the Imider municipality in the Tinghir province of the Drâa-Tafilalet administrative region of Morocco $\left(31.352509^{\circ} \mathrm{N}, 5.832241^{\circ} \mathrm{W}\right)$. Samples were placed at $25^{\circ} \mathrm{C}$ in shade to air-dry for one week and their voucher specimens (THAL-46) were conserved at the laboratory of Microbial Biotechnologies, Agrosciences and Environment, Faculty of Sciences Semlalia, Cadi Ayyad University, Marrakech, Morocco. The identification of this thyme species was carried out by Nafis Ahmed, based on the dichotomous keys of Moroccan flora. Dried leaves were subjected to steam distillation for $3 \mathrm{~h}$ and the preparation of the essential oil was performed three times $(3 \times 50 \mathrm{~g})$. Then, the recovered $\mathrm{EO}$ was stored at $4{ }^{\circ} \mathrm{C}$ in darkness. The yield percentage was calculated as volume (in $\mathrm{mL}$ ) of EO by $100 \mathrm{~g}$ of dried plant material.

\subsection{Gas Chromatography-Mass Spectrometry (GC-MS) Analysis}

The GC-MS system was used to qualitatively and quantitatively characterize the chemical composition of T. atlanticus EO, as previously described [23]. Gas chromatographic coupled to mass spectrometric (GC-MS) analysis was performed on a $1300 \mathrm{GAZ}$ gas chromatograph equipped with a TG-5MS column (30 m length; $0.25 \mathrm{~mm}$ i.d.; $0.25 \mu \mathrm{m}$ film thickness) and coupled to mass selective detector "ISQ Single Quadrupole Mass spectrometer" $(70 \mathrm{eV})$. The analytical conditions were: carrier gas, helium; injection volume was $1 \mu \mathrm{L}$; injector temperature $260^{\circ} \mathrm{C}$, temperature program was $1 \mathrm{~min}$ at $100^{\circ} \mathrm{C}$, ramped from $100{ }^{\circ} \mathrm{C}$ to $260^{\circ} \mathrm{C}$ at $4{ }^{\circ} \mathrm{C} / \mathrm{min}$ and $10 \mathrm{~min}$ at $246^{\circ} \mathrm{C}$. The individual identification of each volatile compound was based on the comparison of the obtained mass spectra 
with NIST and Wiley library reference data and the Kovats retention indices (RI) with a reference library of a series of C 9 to C24 $n$-alkanes.

\subsection{Microorganisms and Culture Conditions}

The antibacterial activity of the EO was evaluated against three Gram-positive bacteria, namely Bacillus subtilis (ATCC 9524), Micrococcus luteus (ATCC 10240), Staphylococcus aureus (CCMM B3) and three Gram-negative bacteria, i.e., Pseudomonas aeruginosa (DSM 50090), Escherichia coli (ATCC 8739) and clinically isolated Klebsiella pneumoniae. In addition, the antifungal activity was assessed using the following four pathogenic yeasts: Candida albicans (CCMM-L4), C. glabrata (CCMM-L7), C. krusei (CCMM-L10) and C. parapsilosis (CCMML18) [24]. The bacterial and yeast species were cultivated for previous use on Muller Hinton agar $\left(\right.$ at $37^{\circ} \mathrm{C}$ ) and Sabouraud dextrose agar (at $28-30^{\circ} \mathrm{C}$ ) plates, respectively.

\subsection{Minimum Inhibitory Concentration (MIC) and Synergistic Effect Determination}

MIC was determined using the two-fold dilution method, as previously described [25]. Briefly, Each microwell was contained $100 \mu \mathrm{L}$ of oil dilution and $100 \mu \mathrm{L}$ of cell suspension prepared by dilution $(1 / 100)$ an overnight culture in MHB and Sabouraud media for bacteria $\left(10^{6} \mathrm{CFU} / \mathrm{mL}\right)$ and yeasts $\left(1-2 \times 10^{3}\right.$ cells $\left./ \mathrm{mL}\right)$, respectively. The MIC value corresponded to the well with the lowest concentration of $\mathrm{EO}$ and without any visible microbial growth. The ciprofloxacin and fluconazol MIC values were also determined.

The synergistic effect between the $\mathrm{EO}$ and ciprofloxacin and fluconazole was evaluated by determining the antibiotic MIC in presence of the $\mathrm{EO}$ at a sub-inhibitory concentration (MIC/4), and the antibiotic MICs were performed using the checkerboard method as previously reported [26]. Briefly, $50 \mu \mathrm{L}$ of the EO (at MIC/4) and each serial two-fold dilution of antibiotics were inoculated with $100 \mu \mathrm{L}$ of a cell suspension of each strain (approximately $10^{6} \mathrm{UFC} / \mathrm{mL}$ ). MIC values were defined as the lowest concentration of antibiotics, in combination with the $\mathrm{EO}$ at MIC/4, inhibiting the visible growth of tested microorganisms. All the tests were performed in triplicate.

To determine the combined effect of antimicrobials and the EO, we calculated the fractional inhibitory concentration index (FICI) which is the most frequently used to define or to describe drug interactions. FICI values were defined according to Odds, 2003 [27]: no interaction (FICI between 0.5 and 4 ), synergy (FICI $\leq 0.5)$ and antagonism (FICI $\geq 4$ ). The MIC gain of antibiotics was calculated as the antibiotic MIC alone divided by the MIC of antibiotic combined with the EO.

\section{Conclusions}

The T. atlanticus EO was characterized by 21 volatile constituents, and carvacrol $(21.62 \%)$ and borneol $(21.13 \%)$ were found to be the most abundant. The EO exhibited a significant antimicrobial activity, with MIC values varying from $0.56 \mathrm{mg} / \mathrm{mL}$ to $4.47 \mathrm{mg} / \mathrm{mL}$. Moreover, EO showed a total synergistic effect with both antibiotics towards all tested strains and the highest gain in term of antibiotic MIC value was reported against $K$. pneumonia, with a 256-fold gain. Our results suggested that the EO extracted from T. atlanticus should be further explored with the aim of investigating its potential use as a tool for the management of multi-drug resistant microorganisms.

Author Contributions: Conceptualization, A.N. and F.E.O.; sampling and taxonomy, A.N.; methodology, A.N., N.M. (Noureddine Mezrioui) and L.H.; data curation, N.M. (Najat Marraiki) and A.M.E.; writing-original draft preparation, A.N.; writing-review and editing, L.C. and M.I.; visualization, L.O.; funding acquisition, L.C. and A.S. All authors have read and agreed to the published version of the manuscript.

Funding: Luísa Custódio acknowledges the Foundation for Science and Technology (FCT) and the Portuguese National Budget for the Multi/04326/2020 project, and for the FCT Scientific Employment Stimulus (CEECIND/00425/2017).

Institutional Review Board Statement: Not applicable. 
Informed Consent Statement: Not applicable.

Data Availability Statement: The data presented in this study are available in the article.

Acknowledgments: The authors extend their appreciation to the researchers supporting project number (RSP-2021/201), King Saud University, Riyadh, Saudi Arabia.

Conflicts of Interest: The authors declare no conflict of interest.

Sample Availability: Samples of the compounds are not available from the authors.

\section{References}

1. Fennane, M.; Ibn Tattou, M.; Ouyahya, A.; El Oualidi, J. Flore pratique du Maroc, Manuel de détermination des plantes vasculaires. Inst. Sci. Rabat 2007, 2, 636.

2. Dobignard, A. Iter maroccanum 2014 de la Société botanique du Centre-Ouest dans le Grand Atlas marocain. Rev. Électron. Annu. Soc. Bot. Cent. Ouest. Evaxiana 2016, 2, 107-252.

3. Soković, M.; Glamočlija, J.; Ćirić, A.; Kataranovski, D.; Marin, P.D.; Vukojević, J.; Brkić, D. Antifungal Activity of the Essential oil of Thymus vulgaris L. and Thymol on Experimentally Induced Dermatomycoses. Drug Dev. Ind. Pharm. 2008, 34, 1388-1393. [CrossRef] [PubMed]

4. Almanea, A.; El-Aziz, G.S.A.; Ahmed, M.M.M. The Potential Gastrointestinal Health Benefits of Thymus Vulgaris Essential Oil: A Review. Biomed. Pharmacol. J. 2019, 12, 1793-1799. [CrossRef]

5. Khouya, T.; Ramchoun, M.; Hmidani, A.; Amrani, S.; Harnafi, H.; Benlyas, M.; Filali Zegzouti, Y.; Alem, C. Anti-inflammatory, anticoagulant and antioxidant effects of aqueous extracts from Moroccan thyme varieties. Asian Pac. J. Trop. Biomed. 2015, 5, 636-644. [CrossRef]

6. Khouya, T.; Ramchoun, M.; Amrani, S.; Harnafi, H.; Rouis, M.; Couchie, D.; Simmet, T.; Alem, C. Anti-inflammatory and anticoagulant effects of polyphenol-rich extracts from Thymus atlanticus: An in vitro and in vivo study. J. Ethnopharmacol. 2020, 252, 112475. [CrossRef]

7. Fadli, M.; Saad, A.; Sayadi, S.; Chevalier, J.; Mezrioui, N.-E.; Pagès, J.-M.; Hassani, L. Antibacterial activity of Thymus maroccanus and Thymus broussonetii essential oils against nosocomial infection-Bacteria and their synergistic potential with antibiotics. Phytomedicine 2012, 19, 464-471. [CrossRef]

8. Kasrati, A.; Alaoui Jamali, C.; Fadli, M.; Bekkouche, K.; Hassani, L.; Wohlmuth, H.; Leach, D.; Abbad, A. Antioxidative activity and synergistic effect of Thymus saturejoides Coss. essential oils with cefixime against selected food-borne bacteria. Ind. Crops Prod. 2014, 61, 338-344. [CrossRef]

9. Saad, A.; Fadli, M.; Bouaziz, M.; Benharref, A.; Mezrioui, N.E.; Hassani, L. Anticandidal activity of the essential oils of Thymus maroccanus and Thymus broussonetii and their synergism with amphotericin B and fluconazol. Phytomedicine 2010, 17, 1057-1060. [CrossRef]

10. Fadli, M.; Bolla, J.-M.; Mezrioui, N.-E.; Pagès, J.-M.; Hassani, L. First evidence of antibacterial and synergistic effects of Thymus riatarum essential oil with conventional antibiotics. Ind. Crops Prod. 2014, 61, 370-376. [CrossRef]

11. Mahboubi, M.; Heidarytabar, R.; Mahdizadeh, E.; Hosseini, H. Antimicrobial activity and chemical composition of Thymus species and Zataria multiflora essential oils. Agric. Nat. Resour. 2017, 51, 395-401. [CrossRef]

12. Gedikoğlu, A.; Sökmen, M.; Çivit, A. Evaluation of Thymus vulgaris and Thymbra spicata essential oils and plant extracts for chemical composition, antioxidant, and antimicrobial properties. Food Sci. Nutr. 2019, 7, 1704-1714. [CrossRef] [PubMed]

13. Zarshenas, M.M.; Krenn, L. A critical overview on Thymus daenensis Celak: Phytochemical and pharmacological investigations. J. Integr. Med. 2015, 13, 91-98. [CrossRef]

14. Memar, M.Y.; Raei, P.; Alizadeh, N.; Akbari Aghdam, M.; Kafil, H.S. Carvacrol and thymol: Strong antimicrobial agents against resistant isolates. Rev. Med. Microbiol. 2017, 28, 63-68. [CrossRef]

15. Marinelli, L.; Di Stefano, A.; Cacciatore, I. Carvacrol and its derivatives as antibacterial agents. Phytochem. Rev. 2018, 17, 903-921. [CrossRef]

16. Sharifi-Rad, M.; Varoni, E.M.; Iriti, M.; Martorell, M.; Setzer, W.N.; del Mar Contreras, M.; Salehi, B.; Soltani-Nejad, A.; Rajabi, S.; Tajbakhsh, M.; et al. Carvacrol and human health: A comprehensive review. Phyther. Res. 2018, 32, 1675-1687. [CrossRef]

17. Yang, L.; Zhan, C.; Huang, X.; Hong, L.; Fang, L.; Wang, W.; Su, J. Durable Antibacterial Cotton Fabrics Based on Natural Borneol-Derived Anti-MRSA Agents. Adv. Healthc. Mater. 2020, 9, 2000186. [CrossRef]

18. Gao, Z.; Van Nostrand, J.D.; Zhou, J.; Zhong, W.; Chen, K.; Guo, J. Anti-listeria Activities of Linalool and Its Mechanism Revealed by Comparative Transcriptome Analysis. Front. Microbiol. 2019, 10, 2947. [CrossRef]

19. Cai, R.; Zhang, M.; Cui, L.; Yuan, Y.; Yang, Y.; Wang, Z.; Yue, T. Antibacterial activity and mechanism of thymol against Alicyclobacillus acidoterrestris vegetative cells and spores. LWT 2019, 105, 377-384. [CrossRef]

20. Oyedemi, S.; Okoh, A.; Mabinya, L.; Pirochenva, G.; Afolayan, A. The proposed mechanism of bactericidal action of eugenol, $\propto$-terpineol and $\gamma$-terpinene against Listeria monocytogenes, Streptococcus pyogenes, Proteus vulgaris and Escherichia coli. Afr. J. Biotechnol. 2002, 8, 1280-1286.

21. Hirsch, E.B.; Tam, V.H. Impact of multidrug-resistant Pseudomonas aeruginosa infection on patient outcomes. Expert Rev. Pharmacoecon. Outcomes Res. 2010, 10, 441-451. [CrossRef] [PubMed] 
22. Pang, Z.; Raudonis, R.; Glick, B.R.; Lin, T.-J.; Cheng, Z. Antibiotic resistance in Pseudomonas aeruginosa: Mechanisms and alternative therapeutic strategies. Biotechnol. Adv. 2019, 37, 177-192. [CrossRef] [PubMed]

23. Nafis, A.; Kasrati, A.; Jamali, C.A.; Mezrioui, N.; Setzer, W.; Abbad, A.; Hassani, L. Antioxidant activity and evidence for synergism of Cannabis sativa (L.) essential oil with antimicrobial standards. Ind. Crops Prod. 2019, 137, 396-400. [CrossRef]

24. Nafis, A.; Oubaha, B.; Elhidar, N.; Ortlieb, N.; Kulik, A.; Niedermeyer, T.; Hassani, L.; Barakate, M. Novel production of two new nonpolyenic antifungal macrolide derivatives by Streptomyces Z26 isolated from moroccan Rhizospheric soil. Online J. Biol. Sci. 2018, 18, 176-185. [CrossRef]

25. Nafis, A.; Kasrati, A.; Jamali, C.A.; Samri, S.E.; Mezrioui, N.; Abbad, A.; Hassani, L. Antioxidative Effect and First Evidence of Synergistic Antimicrobial Effects of Ficus carica (L.) Leaf Essential Oil with Conventional Antibiotics. J. Essent. Oil-Bear. Plants 2019, 22, 1289-1298. [CrossRef]

26. Nafis, A.; Hassani, L.; Marraiki, N.; Al-Rashed, S.; Elgorban, A.M.; Syed, A.; Iriti, M. Antimicrobial and synergistic effect of Moroccan native Argania spinosa essential oil for modulating of antibiotics resistance. Nat. Prod. Res. 2020, 1-5. [CrossRef]

27. Odds, F.C. Synergy, antagonism, and what the chequerboard puts between them. J. Antimicrob. Chemother. 2003, 52, 1. [CrossRef] [PubMed] 